\title{
$\mathrm{R} C \& \mathrm{C}$
}

REVISTA DE CONTABILIDADE E CONTROLADORIA

\section{GRAU DE EVIDENCIAÇÃO DAS INFORMAÇÕES VOLUNTÁRIAS DAS INSTITUIÇÕES DE ENSINO SUPERIOR CONFESSIONAIS E NÃO CONFESSIONAIS}

LEVEL OF VOLUNTARY DISCLOSURE OF RELIGIOUSLY AND NON-RELIGIOUSLY ORIENTED UNIVERSITIES

Recebido em 20.07.2014 | Aceite final em 03.11.2015 |

Nota: este artigo foi aceito pelo Editor Jorge Eduardo Scarpin e passou por uma avaliação double

blind review

A reprodução dos artigos, total ou parcial, pode ser feita desde que citada a fonte.

DAYANE MENDES SANTOS

Graduada em Ciências Contábeis pela UPM | Universidade Presbiteriana Mackenzie | Rua da Consolação, 930 - CEP 01302-090 - São Paulo/SP | Tel. (11) 2114-8000 | Email: dayanemstos@hotmail.com

TATIANE FERREIRA GAIOT Graduada em Ciências Contábeis pela UPM | Universidade Presbiteriana Mackenzie | Rua da Consolação, 930 - CEP 01302-090 - São Paulo/SP | Tel. (11) 2114-8000 | Email: tatiane_gaiot@yahoo.com.br

MARCO ANTONIO FIGUEIREDO MILANI FILHO Doutor em Controladoria e Contabilidade pela USP | Universidade Estadual de Campinas | Rua Pedro Zaccaria, 1300 - CEP 13484-350 - Limeira/SP | Tel. (19) 3701 6663 | E-mail: marco.milani@fca.unicamp.br

\section{RESUMO}

Considerando que as organizações sem fins lucrativos (OSFL) oferecem serviços e programas que, de outra forma, teriam de ser fornecidos pelo governo, elas são isentas ou imunes dos impostos que as empresas com fins lucrativos devem recolher. Por outro lado, as OSFL devem fornecer informações úteis para os seus stakeholders sobre a origem e a utilização dos seus recursos, bem como sobre o desempenho de suas atividades. Há muitas OSFL no setor educacional brasileiro, como as universidades de orientação religiosa. Supondo-se que os valores éticos professados podem influenciar o nível de divulgação voluntária, o objetivo deste estudo foi verificar se havia diferença significativa no nível de divulgação voluntária entre universidades confessionais e não-confessionais privadas. A área 
geográfica escolhida para o estudo foi o estado de São Paulo, o qual possui o maior número de universidades e organizações sem fins lucrativos no Brasil. O ano base da pesquisa foi o de 2012. Baseando-se na revisão bibliográfica, foram utilizados 18 itens relacionados com a divulgação voluntária de informações para se calcular o Indicador de Disclosure (ID) de 30 universidades. Os resultados apontaram que, em média, $64,4 \%$ dos itens de informação voluntária estavam presentes na amostra. A análise comparativa indicou que não havia diferença significativa entre os níveis de divulgação voluntária das universidades confessionais e não-confessionais, sugerindo que os valores éticos professados não conseguem explicar, isoladamente, o nível de divulgação voluntária.

Palavras Chave: Nível de Evidenciação. Terceiro Setor. Universidades. Organizações confessionais.

\begin{abstract}
Because nonprofit organizations (NPO) offer services and programs that would otherwise have to be provided by the government, the government excuses them from the taxes that for-profit businesses must. On other hand, NPO are supposed to provide useful information to their stakeholders about the origin and use of its resources, as well as about their activities performance. There are many NPO in the Brazilian education sector, such as the religiously oriented universities. Assuming that the professed ethical values can influence the level of voluntary disclosure, the objective of this study was to verify whether there was significant difference in the level of voluntary disclosure between religiously and private non-religiously oriented universities. The geographic area chosen for the study was the state of São Paulo, which has the largest number of universities and nonprofit organizations in Brazil. The base year of the survey was 2012. Based on the literature review, 18 items related to voluntary information were used to calculate the indicator of disclosure (ID) of 30 universities. The results indicated that an average of $64.4 \%$ of the voluntary disclosure items were present in the sample. The comparative analysis indicated no significant difference between the levels of voluntary disclosure of religiously and non-religiously oriented universities, and it suggests that the professed ethical values cannot explain solely the level of voluntary disclosure.
\end{abstract}

Keywords: Level of disclosure. Nonprofit sector. Universities. Religiously orientated organizations.

\title{
1 INTRODUÇÃO
}

Com uma demanda crescente para a prestação de informações públicas nas últimas décadas, as entidades do Terceiro Setor, também chamadas de Organizações Sem Fins Lucrativos (OSFL), passaram a adotar diferentes procedimentos para atender às expectativas de seus stakeholders. Por 
um lado, a legislação vigente define os aspectos obrigatórios no processo de divulgação e evidenciação informacionais. Por outro lado, doadores de recursos, agentes da sociedade civil, usuários e demais grupos com interesses legítimos no desempenho das organizações também pressionam por um maior nível de disclosure e consequente redução da assimetria informacional entre as partes.

Segundo Bushman e Smith (2003), a divulgação e evidenciação são essenciais a todos aqueles que dependem de informações para a tomada de decisão e contribui diretamente na avaliação das opções disponíveis para a aplicação de recursos, além de favorecer o monitoramento dos gestores das entidades como um elemento de governança.

Dentre as diferentes áreas de atuação das organizações do Terceiro Setor, a área educacional é uma das mais destacadas, junto com as áreas de saúde, direitos civis e de assistência social. Estrategicamente, a educação possui grande relevância ao desenvolvimento nacional e, por esse motivo, todas as entidades de ensino recebem atenção pública e privada. Conforme a Constituição Federal (BRASIL, 1988), a educação é um dever do Estado e direito do cidadão. Como não é uma área de atuação exclusiva, o próprio Estado pode incentivar a participação de organizações privadas devidamente autorizadas. Dentre as instituições privadas atuantes no ensino superior, as OSFL têm papel de destaque e, dessas últimas, algumas são organizações confessionais. Assim, o Brasil conta com Instituições de Ensino Superior (IES) que podem ser confessionais.

Em virtude da renúncia fiscal em favor das IES e no uso de recursos públicos para aplicação em suas atividades próprias, há exigências específicas para a respectiva prestação de contas a determinados órgãos governamentais.

Nesse contexto, a questão que norteia esta pesquisa é: há diferença significativa no nível de disclosure voluntário das Instituições de Ensino Superior confessionais e das não confessionais?

O objetivo geral é, portanto, verificar se há diferença estatística significativa no nível de divulgação informacional voluntária das IES. O Estado de São Paulo foi a região definida para a delimitação geográfica deste estudo, considerando que é a área que reúne a maior quantidade de IES confessionais do país.

Esta pesquisa se justifica, principalmente, diante da necessidade de divulgação de informações de organizações sem fins lucrativos para a prestação de contas aos órgãos fiscalizadores e à própria sociedade civil, além da ausência de trabalhos específicos sobre esse tema na literatura científica. Espera-se, com os resultados aqui obtidos, contribuir com os diferentes grupos de usuários externos das informações relacionadas às características e ao desempenho dessas organizações, assim como fomentar novos estudos sobre a influência da confessionalidade na transparência e prestação de contas organizacionais.

\section{REFERENCIAL TEÓRICO}

\subsection{EVIDENCIAÇÃO}

A evidenciação (disclosure) é uma das formas mais importantes de comunicação entre a empresa, os seus acionistas e o mercado em geral. Ao munir os investidores e demais interessados com elementos capazes de auxiliar nos respectivos processos analíticos e decisórios, a empresa favorece a governança corporativa (BUSHMAN; SMITH, 2003). Dessa forma, é essencial que as informações referentes aos principais fatos de uma organização sejam disponibilizadas, com qualidade e serventia aos usuários interessados, para que estes possam analisar as organizações e tomar as decisões que Ihes cabem, da melhor forma (BUSHMAN et al., 2004). 
Lanzana (2004, p. 13) aponta que, além da situação patrimonial e financeira de divulgação obrigatória, algumas organizações também divulgam informações voluntárias, tais como estimativas de resultados futuros, apresentações para os analistas, conferências telefônicas, relatórios para a imprensa, websites na Internet, dentre outros relatórios corporativos.

As informações relacionadas à evidenciação das transações realizadas pelas organizações com e sem fins lucrativos atraem a atenção de diferentes usuários, tanto públicos quanto privados. Nesse sentido, as características e o processo da evidenciação (também utilizada como sinônimo de divulgação) têm sido objeto de estudo de pesquisadores. Segundo Niyama e Gomes (1996):

Disclosure [...] diz respeito à qualidade das informações de caráter financeiro e econômico, sobre as operações, recursos e obrigações de uma entidade, que sejam úteis aos usuários das demonstrações contábeis, entendidas como sendo aquelas que de alguma forma influenciem na tomada de decisões, envolvendo a entidade e o acompanhamento da evolução patrimonial, possibilitando o conhecimento das ações passadas e a realização de inferências em relação ao futuro (NIYAMA; GOMES, 1996, p. 65).

Para Board et al. (2002), Baums (2002), Francis et al (2008) e Zhang (2008), dentre outros, a evidenciação é o canal de transmissão das informações da empresa para o mercado e auxilia o processo decisório dos usuários, reduzindo a assimetria entre as partes. Segundo o International Accounting Standards Connittee, o disclosure está diretamente relacionado às características qualitativas das informações contábeis, que as tornam mais úteis e que aumentam a capacidade de avaliação dos usuários para fatores como compreensibilidade, relevância, confiabilidade e comparabilidade (IASC, 2002, p. 49).

Guay e Verrecchia (2007, p. 16) afirmam a importância e a necessidade da divulgação de informações, independentemente do grau de abrangência, sinalizando que, mesmo que seja divulgada uma estimativa do valor da empresa ao invés do valor propriamente dito, divulgar resolve mais incerteza do que sonegar.

Ainda que diversos pesquisadores estejam se debruçando sobre esse tema, Verrecchia (2001) argumenta que inexiste uma teoria unificada da divulgação.

O problema prático é que não há nenhuma teoria da divulgação abrangente ou unificada, ou pelo menos, nenhuma sobre a qual eu me sinta confortável para identificar como tal. Na literatura de divulgação, não existe um paradigma central, nem uma única noção convincente que dá origem a todas as pesquisas posteriores, nenhuma "teoria" bem integrada. (VERRECCHIA, 2001, p. 98).

A evidenciação voluntária vai além do requerido por leis, normas contábeis ou determinações de órgãos reguladores e é um elemento relevante no processo decisório dos usuários informacionais. (WATSON, 2002, p. 289). Por outro lado, Dantas et al. $(2005$, p.56) observam que muitas empresas são resistentes a fornecer informações voluntárias, não somente por questões envolvendo a confidencialidade de informações estratégicas, mas também por uma questão de se evitar gastos adicionais nos processos de coleta, preparo e divulgação.

Healy e Palepu (2001, p. 33) encontraram três tipos de efeitos no mercado, provocados pelo aumento de disclosure voluntário: aumento da liquidez das ações no mercado, reduções no custo de capital próprio e crescimento da atenção por parte dos analistas. Hail (2002, p. 4), apresenta dois pensamentos a respeito da relação entre o custo de capital e o nível de disclosure, onde, num primeiro momento, as empresas visam reduzir o custo de capital próprio divulgando informações privadas (disclosure voluntário), devido à relutância dos investidores em potencial para a realização de suas ações no mercado, já num segundo momento, as empresas visam reduzir a estimação de 
risco por parte dos investidores oferecendo maior nível de disclosure, ou seja, uma melhor divulgação.

ludícibus (2000, p. 121) afirma que as formas de evidenciação podem variar, mas a essência é sempre a mesma, ou seja, apresentar informação quantitativa e qualitativa de forma ordenada, evitando deixar de fora dos demonstrativos formais o menor volume possível de informações, de modo que propicie uma base adequada de informação para o usuário.

Ainda é destacada a discussão sobre os níveis de divulgação propostos - evidenciação adequada, justa ou plena, e ressalta-se o posicionamento de ludícibus (2000, p. 117), de que toda informação para o usuário precisa ser adequada, justa e plena, simultaneamente. É destacado também que ocultar ou fornecer informação demasiadamente resumida é tão prejudicial quanto fornecer informação excessivamente. Neste sentido, o disclosure está diretamente relacionado à relevância e à materialidade que definem os limites e a abrangência do que deve ser evidenciado, mesmo estes conceitos sendo subjetivos, o que pode dificultar a definição do que deve ser evidenciado. $\mathrm{Na}$ questão "quando evidenciar", há uma relação com o conceito de oportunidade da comunicação, ou seja, para uma informação ser útil, ela deve ser disponibilizada ao usuário interessado antes de perder sua capacidade de influenciar a decisão, e mesmo que a oportunidade, por si só, não garanta a relevância da informação, não há relevância sem oportunidade. Por fim, em relação à última questão, "como evidenciar", os métodos de evidenciação são mais abrangentes, cabendo escolher o mais apropriado, conforme a natureza da informação e sua importância relativa como demonstrações financeiras, informações entre parênteses, notas explicativas, quadros e demonstrativos suplementares, parecer da auditoria e relatório da administração.

De acordo com Lima (2009, p. 15) o índice de disclosure é um método aplicado nas pesquisas contábeis, e utilizado para fornecer um número capaz de indicar o nível dos conteúdos dos relatórios de organizações comparáveis ou de aspectos particulares de interesses mencionados por tais relatórios, por exemplo, disclosure voluntário e ambiental. Conforme Nelson et. al. (2003, p. 5), indicador de disclosure é um instrumento para medir a existência de um conjunto de itens específicos e, também, para avaliar a qualidade e a quantidade da divulgação de informações apresentadas.

Segundo Milani Filho (2009, p. 5) as Organizações do Terceiro Setor estão voltadas às ações de interesse público e o disclosure social está relacionado com sua característica operacional. As OTS priorizam a agregação de valor a elas mesmas e também ao cumprimento de sua missão social. Destacam-se pela distribuição de riqueza e a obrigatoriedade de reinvestimento de possíveis superávits que venham a obter. Portanto, o ato de evidenciação de informações sociais deveria ser inerente à natureza das OTS.

\subsection{INSTITUIÇÕES DE ENSINO SUPERIOR}

Nos dias atuais, as rápidas mudanças sociais, políticas, econômicas e culturais na sociedade, têm influenciado a educação superior no país. Segundo Colossi, Consentino e Queiroz (2001):

Educação superior é uma instituição social, cujo papel fundamental é formar a elite intelectual e científica da sociedade a que serve. Uma instituição social caracterizase pela estabilidade e durabilidade de sua missão. Além disso, é estruturalmente assentada em normas e valores emanados do grupo ou sociedade em que se insere. Uma instituição social é, fundamentalmente, um ideal, uma doutrina. Assim, a educação superior é uma instituição social, estável e duradoura, concebida a partir de normas e valores da sociedade. É, acima de tudo, um ideal que se 
destina, enquanto integrador de um sistema, à qualificação profissional e promoção do desenvolvimento político, econômico, social e cultural (COLOSSI; CONSENTINO; QUEIROZ, 2001, p. 51).

De acordo com o artigo 1ำ do Decreto 3.860 (BRASIL, 2001), as Instituições de Ensino Superior são classificadas entre públicas e privadas.

Quanto à organização acadêmica das IES, o artigo 70 do Decreto 3.860 (Brasil, 2001) as classifica em Universidades, Centros Universitários, e Faculdades:

- Universidades são aquelas que ofertam regularmente atividades de ensino, de pesquisa e de extensão. Ainda, no artigo 2070 da Constituição Federal de 1988, as universidades possuem autonomia didático-científica, administrativa e de gestão financeira e patrimonial obedecendo ao princípio da indissociabilidade, ou seja, estas atividades não podem ser separáveis, nem estudadas em partes;

- Centros universitários são instituições de ensino superior pluricurriculares (possuem a exigência em ter mais de dois cursos), caracterizados pela excelência do ensino oferecido, comprovada pelo desempenho de seus cursos, pela qualificação seu corpo docente e pelas condições de trabalho acadêmico oferecido à comunidade escola, e possuem autonomia para criar, organizar e extinguir, em sua sede, cursos e programas de educação superior;

- Faculdades são instituições com propostas curriculares em mais de uma área de conhecimento, organizadas para atuar com regimento comum e comando unificado, e seu credenciamento se dará mediante ato do Poder Executivo.

As Instituições Privadas de Ensino Superior, segundo a Lei 9.394 no artigo 20 (Brasil, 1996) enquadram-se nas seguintes categorias:

Instituição de Ensino Superior privadas com fins lucrativos podem ser particulares em sentido estrito, assim entendidas as que são instituídas e mantidas por uma ou mais pessoas físicas ou jurídicas de direito privado.

Instituição de Ensino Superior privadas sem fins lucrativos podem ser:

I - Comunitárias, que são instituídas por grupos de pessoas físicas ou por uma ou mais pessoas jurídicas, inclusive cooperativas educacionais, que incluam na sua entidade mantenedora representantes da comunidade;

II - Confessionais, que são instituídas por grupos de pessoas físicas ou por uma ou mais pessoas jurídicas que atendem a orientação confessional e ideológica específica;

III - Filantrópicas, que de acordo com Kobs e Reis (2008, p. 10), são instituições de educação ou de assistência social que prestam serviços e os colocam à disposição da população, em caráter complementar às atividades do Estado, sem qualquer remuneração de seus dirigentes estatutários e que não possuem a finalidade de obter lucro.

\subsection{CONFESSIONALIDADE}


Segundo Coenen e Colin (1985, p.465), a palavra confissão já era utilizada pelos gregos como representação de compromisso, promessa ou admissão de situações como verdadeiras e, em um contexto tradicional, pode remeter à compreensão simples da admissão de algo ou ao reconhecimento da veracidade de determinado fato ao qual se confessa. É possível ainda que o termo evoque a noção de reconhecimento e declaração de culpa, sinal de arrependimento e conversão, e assim por diante. Dessa maneira, o termo remete a um ato de comprometer-se.

Nascimento (2003, p. 37) define confessionalidade como o neologismo derivado de confissão, ou seja, que tem qualidade religiosa, tomado de crença, de confissão de fé. $O$ autor também coloca que convicção é a base para tratar de uma educação confessional, pois, se confessa o que é acreditado ou aquilo em que se deve acreditar. Já para Alvin (1995, p. 78), a confessionalidade faz parte do indivíduo e, portanto, está presente onde ele estiver, inclusive na escola, na educação, mesmo que se apresente de diferentes maneiras e que dependa de cada situação. Sob essa perspectiva, faz-se necessário que a confessionalidade seja construída em meio a um espaço de liberdade e de diálogo.

Quanto às universidades que se declaram confessionais, segundo Borges (2008, p. 33), é importante que estas saibam, de forma clara, o que representa ser uma instituição de ensino superior que carrega influências da confessionalidade, pois essas instituições confessam publicamente que possuem uma fé comum e que essa fé se expressará em realizações que tragam mudanças significativas num enfoque global no qual estão inseridas. Estas instituições tratam de uma confissão no enfoque da educação superior e de confessionalidade em universidade em meio à globalização.

Portanto, é de extrema importância, que as instituições de essência confessional, tenham compreendido bem claramente as implicações consequentes dessa essência (BORGES, 2008, p. 31).

\subsection{DISCLOSURE EM INSTITUIÇÕES DE ENSINO SUPERIOR}

Coy et al. (2001), afirmam que:

Por causa do seu papel na comunidade, universidades e faculdades têm uma accountability ampla em termos do que é registrado e para quem. Entidades do setor público são formadas pelo público, fundo de bolsas públicas, incluindo doações privadas e estatais e fornecem serviços para a comunidade como um todo. Por essas razões, os stakeholders incluem todos os membros da comunidade. Por causa do impacto das faculdades e universidades na vida de muitos cidadãos, ambos como destinatários dos serviços e a grande quantia de recursos públicos consumidos, suas obrigações de accountability são extensivas. (COY et al., 2001, p. 11)

Coy et al (2001) defendem a utilização da accountability pública para as instituições de ensino como direito do povo de receber informações para que possam debater a questão que afeta a todos. Para os autores, a utilidade de decisão é dominante dos relatórios externos contábeis, e esses provavelmente satisfazem os envolvidos nas relações comercias com faculdades e universidades, e ajudam em decisões sobre empréstimos, negócios e afins.

A escassez de informações sobre o desempenho das IES privadas, entretanto, é destacada por autores como Lima (2009), o qual observa que muitos stakeholders de faculdades e universidades carecem de dados sobre o desempenho dessas instituições. Por outro lado, Engstron e Fountain (1989) enfatizam que a simples divulgação de relatórios genéricos não supriria a demanda informacional dos diferentes públicos interessados nos resultados financeiros e nas métricas relacionadas às atividades de ensino, pesquisa e extensão. 
Os stakeholders, de modo geral, estão interessados em confirmar se os recursos foram usados de forma econômica, eficiente e efetiva de acordo com os propósitos prescritos, na avaliação da habilidade e de recursos necessários para que a entidade possa fornecer serviços no futuro e a natureza e os custos desses serviços (COY et al, 2001; ENGSTRON e FOUNTAIN, 1989).

Segundo os mesmos autores, a publicação rotineira de relatórios mais compreensivos, poderia melhorar o profissionalismo do corpo docente da universidade. Profissionais dessas instituições poderiam usar essas informações como parte de suas análises para possíveis avanços e submeteremse a exame público mais aberto e progressivo. O ensino superior pode explicitar os tipos de informação que demonstram os benefícios do processo educacional, interligado a uma accountability aprimorada. Complementam, ainda, que a prestação de contas nos relatórios externos pode auxiliar as entidades sem fins lucrativos a aprimorar a comunicação com os seus stakeholders.

\section{ASPECTOS METODOLÓGICOS}

Este trabalho se classifica como pesquisa descritiva quanto aos objetivos e como pesquisa documental quanto aos procedimentos de investigação. É de natureza qualitativa já que a fonte de dados é o conjunto de relatórios disponibilizados pelas IES e a respectiva análise de conteúdo. Posteriormente, foram utilizados instrumentos quantitativos para a inferência dos resultados.

Beuren et al. (2009) explicam que nas pesquisas descritivas o objetivo é descrever características de determinada população ou fenômeno ou o estabelecimento de relações entre variáveis. Busca informar sobre situações, fatos, opiniões ou comportamentos da população analisada. Gil (2008), destaca que documentos como relatórios de empresas, dentre outros, já foram processados, mas podem receber outras interpretações, caracterizando-se como objetos de pesquisa documental. A pesquisa quantitativa é o emprego de instrumentos estatísticos, na coleta e no tratamento dos dados, com o objetivo de descobrir e identificar a relação entre variáveis e a relação de causalidade entre fenômenos. A pesquisa qualitativa é aquela na qual o pesquisador desenvolve conceitos, ideias e entendimentos baseados em padrões presentes nos dados e que resultam aspectos subjetivos assim como atingem motivações implícitas, portanto, são utilizadas na busca de entendimentos a respeito da natureza geral de uma questão (BEUREN et al, 2009).

\subsection{CÁlCULO DO NÍVEL DE DISCLOSURE}

Os itens referentes ao disclosure voluntário basearam-se no trabalho de Milani Filho (2009), o qual propôs critérios específicos para a avaliação de organizações sem fins lucrativos. Após a adequação dos elementos pertinentes às IES, foram selecionados 18 itens que apresentaram relação direta com o contexto desta pesquisa, conforme observado no Quadro 1.

Quadro 1 - Itens de divulgação voluntária

\begin{tabular}{llll}
\hline Número & Sigla & Nomes dos Itens & Fonte \\
\hline
\end{tabular}




\begin{tabular}{rllc}
\hline 1 & HIST & História da entidade & Enc e Mak, Bhojraj \\
2 & SERV & Descrição dos serviços prestados & Botosan, Enc e Mak \\
3 & META & Metas e objetivos & Botosan, Enc e Mak \\
4 & FCSU & Fatores críticos de sucesso & Enc e Mak \\
5 & EVEN & Eventos importantes no ano & Hail, Enc e Mak \\
6 & ESTR & Estrutura organizacional & Lanzana, Bhojraj \\
7 & RELA & Relatório de atividades & Hail \\
8 & INRH & Investimentos em recursos humanos \\
9 & SUMA & Sumário dos resultados históricos & Bhojraj \\
10 & CCAP & Custos da atividade de captação de recursos & Bhojraj \\
11 & RECB & Evidenciação dos recursos com finalidade exclusiva & Enc e Mak \\
12 & FUNC & Número de funcionários remunerados & Hail \\
13 & SATU & Satisfação dos usuários dos serviços & Hail \\
14 & SATF & Satisfação dos funcionários & Enc e Mak \\
15 & PINV & Políticas e Projetos e investimentos & Enc e Mak, Bhojraj \\
16 & PROJ & Resultados e desempenhos projetados & Bhojraj \\
17 & WEBS & Informações gerais disponíveis em website & Bhojraj \\
\hline 18 & MISS & Declaração da missão da organização &
\end{tabular}

Fonte: adaptado de Milani Filho, 2009.

O indicador de disclosure voluntário da organização (IDV) é calculado conforme a soma dos itens presentes, com valor máximo de 18. O nível de disclosure da organização (DISC) representa a proporção de itens presentes, calculado pela relação DISC = IDV/18*100.

A população estudada nesta pesquisa é discreta e finita, formada pelas IES (somente universidades) com e sem fins lucrativos, confessionais e não confessionais do estado de São Paulo. Conforme é demonstrado nos quadros 2 e 3, foram identificadas 30 universidades com registro ativo no MEC, das quais $10 \mathrm{com}$ fins lucrativos e $20 \mathrm{sem}$ fins lucrativos. Para análise, as IES sem fins lucrativos foram subdivididas em dois grupos: confessionais (11 instituições) e não confessionais ( 9 instituições).

Quadro 2 - Elementos da Amostra

\begin{tabular}{ll}
\hline \multicolumn{1}{c}{ Elementos } & \multicolumn{1}{c}{ Descrição } \\
\hline População & Instituições de Ensino Superior Privadas com e sem Fins Lucrativos \\
Classificação de IES & Universidades \\
Universo & 30 Instituições sendo: \\
& 20 Instituições sem Fins Lucrativos (11 confessionais e 9 não confessionais) \\
& 10 Instituições com Fins Lucrativos \\
Extensão geográfica & Estado de São Paulo \\
Extensão temporal & 2012 \\
\hline
\end{tabular}

Fonte: Elaborado pelos autores

O Quadro 3 apresenta a relação das IES consideradas conforme a natureza confessional (sim ou não) e a finalidade de lucro (com ou sem).

Quadro 3 - Nome das Instituições e Classificação

\begin{tabular}{|c|c|c|c|c|c|}
\hline Instituição & Confessional & Fins lucrativos & Instituição & Confessional & Fins lucrativos \\
\hline
\end{tabular}




\begin{tabular}{llllll}
\hline UNIABC & Não & Com & PUCCAMP & Sim & Sem \\
UNOESTE & Não & Sem & PUCSP & Sim & Sem \\
USC & Sim & Sem & UAM & Não & Com \\
UNIVAP & Não & Sem & UNIBAN & Não & Com \\
UNG & Não. & Sem & UBC & Não & Com \\
UNIB & Não & Sem & UNICASTELO & Não & Sem \\
UNIMEP & Não & Sem & UNISANTOS & Sim & Sem \\
UMESP & Não & Sem & UNICID & Não & Com \\
UNIMES & Não & Sem & UNICSUL & Não & Com \\
UNINOVE & Não & Sem & UNIFRAN & Não & Com \\
UNIP & Não & Sem & UNIMAR & Não & Com \\
MACKENZIE & Sim & Sem & UMC & Não & Com \\
UNISANTA & Não & Sem & UNAERP & Sim & Sem \\
USF & Sim & Sem & UNISA & Sim & Sem \\
USJT & Sim & Com & UNISO & Sim & Sem \\
\hline
\end{tabular}

Fonte: Elaborado pelos autores

\subsection{COLETA DE DADOS}

Os dados de divulgação voluntária foram verificados e coletados nos relatórios anuais e das informações divulgadas publicamente nos websites das Instituições de Ensino. Além da explicitação do vínculo confessional da mantenedora, os aspectos de confessionalidade das IES foram identificados na história, nos princípios e nos valores divulgados pelas mesmas.

\subsection{APLICAÇÃO E INTERPRETAÇÃO DO TESTE ESTATÍSTICO}

Neste trabalho foi aplicado o teste estatístico de Mann-Whitney. Este teste, segundo Hackbarth e Stein $(2003$, p. 7), é utilizado para comparar dois grupos independentes e a variável deve ser de mensuração ordinal. O teste foi realizado com a utilização do programa Statistical Package for the Social Sciences - SPSS. Os grupos analisados neste trabalho, num primeiro momento, foram as IES privadas com e sem fins lucrativos e, num segundo momento, as IES confessionais e as não confessionais que pertencem ao grupo privadas sem fins lucrativos. Para as IES confessionais foi definido o número 1 e para as IES não confessionais foi definido o número 0 , para efeitos de classificação, assim como para as sem fins lucrativos também foi definido o número 1 e para as com fins lucrativos foi definido o número 0 . Na aplicação do teste não paramétrico de duas amostras simples independentes, foi definida a pontuação como variável e a classificação como grupo. A variável é o grau de evidenciação destes grupos analisados, com o objetivo de comparar os dados encontrados e verificar se há diferença significativa entre eles.

Após interpretar os resultados dos testes foi possível responder a questão de pesquisa que direcionou este trabalho. $O$ nível de significância utilizado foi de $5 \%$ e, de acordo como teste MannWhitney, valores superiores a 0,05 , indicam não haver diferença significativa entre as médias analisadas.

\section{ANÁLISE DE DADOS}


A partir da coleta de dados e do tratamento dos mesmos, utilizando um nível de significância de $5 \%$, foi possível chegar às conclusões a respeito do nível de disclosure dos grupos estudados. As conclusões abaixo foram baseadas nos valores sig ou p-value (valor p), que, segundo Fávero (2009), corresponde à probabilidade associada ao valor observado da amostra, ou seja, ele indica o menor nível de significância observado que levaria à rejeição da hipótese nula (pois haverá igualdade entre as médias).

A seguir, a primeira tabela (Classificações) apresenta a média e a soma dos postos para cada grupo, enquanto que a segunda tabela (Test Statistics) apresenta as estatísticas do teste (FÁVERO, 2009). No primeiro teste, verificou-se se a finalidade lucrativa ou não lucrativa da IES influencia na divulgação de informações.

\section{Tabela 1 - Teste Universidades com e sem Fins Lucrativos}

Mann-Whitney Test

\begin{tabular}{|rl|r|r|r|}
\hline \multicolumn{5}{|c|}{ Classificações } \\
\hline \multirow{4}{*}{ Classificação } & \multicolumn{1}{|c|}{ N } & Mean Rank & Sum of Ranks \\
\hline \multirow{2}{*}{ Pontuação } &, 00 & 10 & 14,00 & 140,00 \\
& 1,00 & 20 & 16,25 & 325,00 \\
& Total & 30 & & \\
\hline
\end{tabular}

\begin{tabular}{|l|r|}
\hline \multicolumn{2}{|c|}{ Test Statistics $^{\mathbf{a}}$} \\
\hline Mann-Whitney U & Pontuação \\
Wilcoxon W & 85,000 \\
Z & 140,000 \\
Sig. Assint. (2 caudas) &,- 665 \\
Sig exata [2*(Sig. de 1- &, 506 \\
cauda)] &, $530^{\mathrm{b}}$ \\
\hline
\end{tabular}

a. Variável de agrupamento: Classificação

b. Não corrigido para vínculos.

Conforme a Tabela 1, foram analisados os resultados das 30 IES com e sem fins lucrativos e observou-se que o fato da instituição não visar o lucro não influenciou significativamente a divulgação de maior número de itens voluntários, ou seja, com um valor de significância de 0,506, superior ao nível de 0,05 determinado para esta análise, não se encontrou evidência estatística de diferença entre os níveis de disclosure.

No segundo teste, verificou-se se a confessionalidade da IES influenciaria a divulgação de informações. Conforme a Tabela 2, foram analisados os resultados das 20 IES confessionais e não confessionais sem fins lucrativos e os resultados indicaram que não há influência significativa na divulgação de itens voluntários em maior quantidade. O valor de significância de 0,155 , superior ao nível de 0,05 determinado para esta análise, sinaliza a inexistência de diferença significativa entre as médias.

Tabela 2 - Teste Universidades Confessionais e não Confessionais sem Fins Lucrativos 
Mann-Whitney Test

\begin{tabular}{|rl|r|r|r|}
\hline \multicolumn{5}{|c|}{ Classificações } \\
\hline \multirow{3}{*}{ Classificação } & N & Mean Rank & Sum of Ranks \\
\hline \multirow{2}{*}{ Pontuação } & 00 & 9 & 8,44 & 76,00 \\
& 1,00 & 11 & 12,18 & 134,00 \\
& Total & 20 & & \\
\hline
\end{tabular}

\begin{tabular}{|l|r|}
\hline \multicolumn{2}{|c|}{ Test Statistics $^{\mathbf{a}}$} \\
\hline \multicolumn{2}{|c|}{ Pontuação } \\
\hline Mann-Whitney U & 31,000 \\
Wilcoxon W & 76,000 \\
Z & $-1,423$ \\
Sig. Assint. (2 caudas) &, 155 \\
Sig exata [2*(Sig. de 1- &, $175^{\mathrm{b}}$ \\
cauda)] & \\
\hline
\end{tabular}

a. Variável de agrupamento: Classificação

b. Não corrigido para vínculos.

Num segundo momento, observou-se nos itens de divulgação voluntária, que quatro instituições apresentaram todos os 18 itens de disclosure voluntário, e que a quantidade mínima de itens apresentados foi igual a cinco, encontrada em uma das instituições, representando $27,78 \%$ dos itens totais. A média da frequência desses itens foi de $64,44 \%$.

Verifica-se na Tabela 3 a frequência dos itens de divulgação voluntária considerando todas as instituições de ensino da amostra como base.

Tabela 3 - Frequência de itens voluntários de disclosure

\begin{tabular}{llllll}
\hline $\mathbf{N}^{\mathbf{o}}$ & Item & Participação & $\mathbf{N}^{\mathbf{o}}$ & Item & Participação \\
\hline 1 & HIST & $100,00 \%$ & 10 & CCAP & $16,67 \%$ \\
2 & SERV & $100,00 \%$ & 11 & RECB & $20,00 \%$ \\
3 & META & $66,67 \%$ & 12 & FUNC & $46,67 \%$ \\
4 & FCSU & $96,67 \%$ & 13 & SATU & $43,33 \%$ \\
5 & EVEN & $100,00 \%$ & 14 & SATF & $26,67 \%$ \\
6 & ESTR & $80,00 \%$ & 15 & PINV & $56,67 \%$ \\
7 & RELA & $80,00 \%$ & 16 & PROJ & $16,67 \%$ \\
8 & INRH & $53,33 \%$ & 17 & WEBS & $100,00 \%$ \\
9 & SUMA & $70,00 \%$ & 18 & MISS & $86,67 \%$ \\
\hline
\end{tabular}

Fonte: Elaborado pelos autores

Os mais frequentes estão presentes em $100 \%$ das entidades, e são: história da entidade (HIST); descrição dos serviços prestados (SERV); eventos importantes no ano (EVEN); informações gerais disponíveis em websites (WEBS); e um item presente em 96,67\%, que é: fatores críticos de sucesso (FCSU). Por outro lado, verificaram-se quatro itens que são menos frequentes nas instituições, a saber: custos da atividade de captação de recursos (CCAP); evidenciação de recursos com finalidade exclusiva (RECB); satisfação dos funcionários (SATF); resultados e desempenhos projetados (PROJ).

\section{CONCLUSÃO}


O objetivo geral deste trabalho foi atingido ao se verificar se havia diferença significativa no nível de disclosure voluntário das IES confessionais e não confessionais, por meio da aplicação de um modelo de cálculo para o nível de divulgação dessas organizações no Estado de São Paulo.

Os resultados indicaram que não há diferença significativa entre os níveis de disclosure dos grupos analisados. De acordo com os testes estatísticos realizados, a natureza sem fins lucrativos e o vínculo religioso da mantenedora não representam fatores determinantes para se diferenciar o grau de evidenciação das entidades. Dessa maneira, não foi confirmada a suposição de que a confessionalidade e a orientação não lucrativa poderiam influenciar na quantidade de itens voluntários divulgados.

Foi possível constatar que o nível de disclosure voluntário da amostra utilizada alcançou uma média de $64,44 \%$, ou seja, dos 18 itens selecionados, as IES apresentaram cerca de 12 itens esperados. De todos os itens, quatro estavam presentes em 100\% das IES analisadas, a saber: HIST (história da entidade), SERV (descrição dos serviços prestados), EVEN (eventos relevantes) e WEBS (informações gerais disponíveis em website). Os itens menos presentes, encontrados em apenas 16,67\% das IES, foram as informações relacionadas à CCAP (custos da atividade de captação de recursos) e PROJ (resultados e desempenhos projetados). Esses resultados permitem supor que a maioria das IES analisadas enfatizam mais o passado do que as perspectivas e cenários futuros.

Sugere-se para estudos futuros a comparação dos itens de divulgação voluntária das IES de outros estados brasileiros e, também, de outros países.

\section{REFERÊNCIAS}

ALVIM, Gustavo. Autonomia universitária e confessionalidade. 2.ed. Piracicaba: Ed. Unimep, 1995.

BAUMS, Theodor. Changing patterns of corporate disclosure in continental Europe: The example of Germany. European Corporate Governance Institute (EGCI) - Law Working Paper. Social Science Research Network, 2002.

BEUREN, Ilse M. et al. Como elaborar trabalhos monográficos. 3. ed. São Paulo: Atlas, 2009

BOARD, John et al. Transparency and fragmentation: financial market regulation in a dynamic environment. Houndmills: Palgrave Macmillan, 2002.

BORGES, Inez Augusto. Confessionalidade e Construção Ética na Universidade. São Paulo: Mackenzie, 2008.

BRASIL. Constituição da República Federativa do Brasil de 1988. Disponível em:<http://www.planalto.gov.br/ccivil_03/constituicao/constituicao.htm>. Acesso em: 29 ago. 2013.

BRASIL. Decreto no 3.860, de 9 de julho de 2001. Dispõe sobre a organização do ensino superior, a avaliação de cursos e instituições, e dá outras providências. Disponível em: <http://www.planalto.gov.br/ccivil_03/decreto/2001/D3860.htm>. Acesso em: 18 set. 2013.

BRASIL. Lei no 9.394, de 20 de dezembro de 1996. Estabelece as diretrizes e bases da educação nacional. Disponível em: <http://www.planalto.gov.br/ccivil_03/leis/L9394.htm>. Acesso em: 18 set. 2013.

BUSHMAN, Robert $M$. et al. What determines corporate transparency? Journal of Accounting Research, v. 42, n. 2, May. 2004.

BUSHMAN, Robert M.; SMITH, Abbie J. Transparency, Financial AccountingInformation, and Corporate Governance .FRBNY Economic Policy Review, 2003. 
COENEN, Lothare; COLIN, Brow. Dicionário internacional de teologia do Novo Testamento. São Paulo: Vida Nova, 1985.

COLOSSI, Nelson; CONSENTINO, Aldo; QUEIROZ, Etty G. Mudanças no contexto do ensino superior no Brasil: uma tendência ao ensino colaborativo. Revista FAE, Curitiba, v.4, n.1, p.49-58, jan./abr. 2001.

COY, David; FISCHER, Mary; GORDON, Teresa. Public accountability: a new paradigm for college and university annual reports. Critical Perspectives on Accounting, [S.I], n. 12, p. 1-31, 2001.

DANTAS, José A. et al. dualidade entre os benefícios do disclosure e a relutância das organizações em aumentar o grau de evidenciação. E \& G Economia e Gestão, Belo Horizonte, v. 5, n. 11, p. 56-76, dez. 2005.

ENGSTRON, J.H.; FOUNTAIN, J.R. College and University Financial Reporting: A Survey of Important Financial Decision Makers. Government Accountants' Journal, 38 (2), 39-49, 1989.

FÁVERO, Luiz Paulo [et al.]. Análise de dados: modelagem multivariada para tomada de decisões.Rio de Janeiro: Elsevier, 2009.

FRANCIS, Jennifer; NANDA, Dhananjay; OLSON, Per. Voluntarily disclosure, information quality, and costs of capital. Journal of Accounting Research, v. 46, p. 53-99, 2008.

GIL, Antonio Carlos. Como elaborar projetos de pesquisa. 4. ed. São Paulo: Atlas, 2008.

GUAY, Wayne R.; VERRECCHIA, Robert E. Conservative Disclosure. The Wharton School University of Pennsylvania, Philadelphia. June, 2007.

HACKBARTH NETO, Arthur Alexandre; STEIN, Carlos Efrain. Uma abordagem dos testes nãoparamétricos com utilização do excel. 2003. Disponível em: < www.mat.ufrgs.br/ viali/estatistica/.../artigo_11_09_2003.pdf>. Acesso em 2 out. 2013.

HAIL, Luzi. The impact of voluntary corporate disclosures on the ex ante cost of capital for swiss firms. European Accounting Review, v. 11, n. 4, p.741-773, 2002.

HEALY, Paul. M.; PALEPU, Krishna.G..A review of the empirical disclosure literature. Journal of Accounting \& Economics, n. 31, p.405-440, 2001.

INTERNATIONAL ACCOUNTING STANDARD COMMITTEE (IASC). Normas Internacionais de Contabilidade 2001. Tradução da obra International Accounting Standard 2001, coordenada pelo Ibracon. São Paulo: Ibracon, 2002.

IUDíCIBUS, Sergio. Teoria da Contabilidade. 6e ed. São Paulo: Atlas, 2000.

KOBS, Fabio F.; REIS, Dálcio R. Gestão nas instituições de ensino superior privado. Gestão: Revista Científica de Administração e Sistemas de Informação / Unidade de Ensino Superior Expoente, Curitiba, v. 10, n.10, jan./jun. 2008.

LANZANA, Ana P. Relação entre disclosure e governança corporativa das empresas brasileiras. 2004, 161 p. Dissertação (Mestrado). Universidade de São Paulo, 2009.

LIMA, Emanoel M. Análise comparativa entre o índice disclosure e a importância atribuída por stakeholders a informações consideradas relevantes para fins de divulgação em instituições de ensino superior filantrópicas do Brasil: uma abordagem da teoria da divulgação. 2009. 201p. Tese (Doutorado). Universidade de São Paulo, 2009.

LIMA, Emanoel e Pereira, Carlos. Índice de disclosure das instituições filantrópicas de Ensino Superior do Brasil. Rev. Portuguesa e Brasileira de Gestão, Jan 2012, vol.11, n.1, p.26-40. 
MILANI FILHO, Marco A. F. Eficiência produtiva no terceiro setor: um estudo comparativo de desempenho entre organizações filantrópicas asilares. 2009. 220 p. Tese (Doutorado). Universidade de São Paulo, 2009.

NASCIMENTO, Amós. Reflexões preliminares sobre educação e confessionalidade. Revista Educação e Missão, São Paulo, n.1, 2003.

NELSON, Morton. et al. Improved accountability disclosures by Canadian universities. Canadian Accounting Perspectives, v. 2, n. 1, p. 77-108, 2003.

NIYAMA, Jorge Katsumi; GOMES, Amaro L. Oliveira. Contribuição ao aperfeiçoamento dos procedimentos de evidenciação contábil aplicáveis às demonstrações financeiras de bancos e instituições assemelhadas. In: CONGRESSO BRASILEIRO DE CONTABILIDADE, 15, 1996, Brasília. Anais. Brasília: CFC, 1996.

VERRECCHIA, Robert E. Essays on Disclosure. Journal of Accounting and Economics, v. 32, 97-180, 2001.

WATSON, Anna et al. Voluntary disclosure of accounting ratios in the UK. British Accounting Review, v. $34,2002$.

ZHANG, Jidong. Corporate competitive strategy voluntary disclosure and company characters. Social Science Research Network, 2008. 